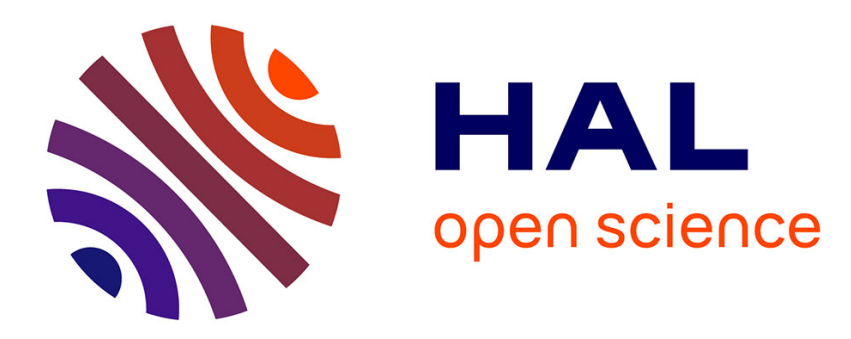

\title{
An estimate of maximum ground surface motion
}

Alain Pecker

\section{To cite this version:}

Alain Pecker. An estimate of maximum ground surface motion. Comptes Rendus Mécanique, 2003, 331, pp.661-666. 10.1016/j.crme.2003.08.001 . hal-00111391

\section{HAL Id: hal-00111391 https://hal.science/hal-00111391}

Submitted on 18 Jul 2019

HAL is a multi-disciplinary open access archive for the deposit and dissemination of scientific research documents, whether they are published or not. The documents may come from teaching and research institutions in France or abroad, or from public or private research centers.
L'archive ouverte pluridisciplinaire HAL, est destinée au dépôt et à la diffusion de documents scientifiques de niveau recherche, publiés ou non, émanant des établissements d'enseignement et de recherche français ou étrangers, des laboratoires publics ou privés. 


\title{
An estimate of maximum ground surface motion
}

\author{
Alain Pecker ${ }^{\mathrm{a}, \mathrm{b}}$ \\ ${ }^{a}$ Géodynamique et structure, 157, rue des Blains, 92220 Bagneux, France \\ b Laboratoire de mécanique des solides, École polytechnique, 91128 Palaiseau cedex, France
}

\begin{abstract}
The increasing need for probability seismic hazard assessment (PSHA) of critical facilities sometimes leads to unrealistic earthquake scenarios with very high induced ground motions. From a physical standpoint these high motions cannot exist because of the limiting resistance capacity of the soil strata through which the seismic waves travel. A simple analytical model is proposed to estimate a bound to the maximum ground surface acceleration that any soil deposit can transfer.
\end{abstract}

\section{Résumé}

Estimation du mouvement sismique maximal à la surface du sol. La demande croissante d'études probabilistes de l'aléa sismique pour les installations essentielles pour la sûreté conduit parfois à des scénarios sismiques irréalistes donnant naissance à des mouvements très élevés. D'un point de vue physique ces mouvements ne peuvent exister en raison de la capacité de résistance limitée des couches de sol que traversent les ondes sismiques. Un modèle analytique simple est proposé pour estimer l'accélération maximale en surface que tout profil de sol est susceptible de transmettre.

Keywords: Soils; Earthquake; Wave propagation; Soil strength

Mots-clés : Sols ; Séisme; Propagation d'ondes ; Résistance du sol

\section{Version française abrégée}

La demande croissante d'études probabilistes de l'aléa sismique pour les installations essentielles pour la sûreté conduit à considérer des scénarios sismiques présentant des probabilités d'occurrence de l'ordre de $10^{-7}$ par an donnant parfois naissance à des mouvements très élevés, qui calculés sur la base d'extrapolations de lois d'atténuation statistiques, peuvent atteindre plusieurs $g$. D'un point de vue physique ces mouvements ne peuvent exister car la capacité de résistance limitée des couches de sol, que traversent les ondes sismiques, limite les mouvements susceptibles d'être transmis. Un modèle analytique simple est proposé pour estimer l'accélération

E-mail address: alain.pecker@geodynamique.com (A. Pecker). 
maximale en surface que tout profil de sol est susceptible de transmettre. Une loi de comportement de type élastique parfaitement plastique est prise en compte pour la couche de sol qui repose sur un substratum infiniment raide; la célérité des ondes dans la couche de sol varie comme une fonction puissance de la profondeur. Le calcul de la déformation induite par la propagation des ondes sismiques est conduit de façon analytique sur la base des modes propres et est comparée, à toute profondeur, à la déformation à rupture du sol. Par affinité sur le mouvement incident à la base de la couche de sol, représenté par son spectre de réponse, on recherche la valeur pour laquelle la déformation à rupture est atteinte à une profondeur quelconque et on en déduit analytiquement la valeur maximale de l'accélération en surface de la couche. La comparaison avec des enregistrements réels de séisme et avec des calculs numériques montre la bonne capacité de prédiction de la méthode.

\section{Introduction}

The increasing use of Probabilistic Seismic Hazard Assessment (PSHA) for critical facilities leads to the consideration of earthquake scenarios with a probability of occurrence as low as $10^{-7}$ per year. For such low probabilities the computed ground accelerations, based on extrapolations of statistical attenuation relationships, may reach values as high as a few $g$ 's, which pose tremendous difficulties for earthquake resistance design. Obviously such large motions cannot exist because the soil profile, through which the seismic waves travel to reach the ground surface, has a limited resistance capacity and cannot transmit any motion. When failure is reached at any depth within the soil profile, the incident motion is filtered and no motion larger than the motion reached at that stage can be transmitted to the upper strata. The soil acts as a fuse to safely limit the maximum ground surface acceleration. It is therefore necessary to develop an approach that takes into account the soil resistance to derive an upper bound estimate of the ground surface motion.

Some authors have tentatively developed such an approach (Betbeder Matibet [1]), but their solution is strongly dependent on the soil stress-strain curve and the associated parameters, which are difficult parameters to measure and to reliably assess. The approach developed herein aims at circumventing those difficulties; it is based on an analytical solution to the wave equation in an inhomogeneous soil profile and provides an estimate of the maximum ground surface acceleration. It is realized that the maximum ground surface acceleration is not the sole meaningful parameter, and that response spectra would represent a more complete description of the surface motion, but, nevertheless, it is believed that the results presented below are useful for PSHA.

\section{Equation of motion}

Let us consider a soil layer of finite thickness overlying a stiff bedrock, which, for the purpose of this study, will be considered as a rigid boundary. In a first step, the soil is assumed to be isotropic elastic, with a shear wave velocity increasing with depth according to some power law:

$$
V(z)=V_{\mathrm{s}}\left(\frac{z}{h}\right)^{p / 2}
$$

where $h$ is the layer thickness and $V_{\mathrm{s}}$ the shear wave velocity at depth $h$. The wave equation for a plane vertically incident shear wave can be written:

$$
\frac{\partial^{2} u}{\partial z^{2}}+\frac{p}{z} \frac{\partial u}{\partial z}-\frac{1}{V_{\mathrm{s}}^{2}}\left(\frac{h}{z}\right)^{p} \frac{\partial^{2} u}{\partial t^{2}}=\frac{1}{V_{\mathrm{s}}^{2}}\left(\frac{h}{z}\right)^{p} \frac{\mathrm{d}^{2} v_{\mathrm{g}}}{\mathrm{d} t^{2}}
$$

where $u$ is the horizontal displacement, relative to the bedrock, and $v_{\mathrm{g}}$ the bedrock motion. The boundary conditions express that the relative displacement at the bedrock interface and the shear stress at the ground surface are equal to 0 :

$$
\begin{array}{ll}
z=0, & \lim _{z \rightarrow 0} G(z) \frac{\partial u}{\partial z}=0 \\
z=h, & u=0
\end{array}
$$


In Eq. (3a) $G(z)$ is the shear modulus related to the shear wave velocity by the relationship $G(z)=\rho V^{2}(z)$, where $\rho$ is the soil mass density, assumed constant over depth.

Eq. (2) is solved with the mode superposition technique. The modes equation can be written:

$$
\frac{\mathrm{d}^{2} X}{\mathrm{~d} z^{2}}+\frac{p}{z} \frac{\mathrm{d} X}{\mathrm{~d} z}+\frac{\omega^{2}}{V_{\mathrm{s}}^{2}}\left(\frac{h}{z}\right)^{p} X=0
$$

and its solution is given by $(p<2)$ :

$$
X=A z^{(1-p) / 2} \mathbf{J}_{(p-1) /(2-p)}\left[\frac{2 \omega h^{p / 2}}{V_{\mathrm{s}}(2-p)} z^{(2-p) / 2}\right]
$$

where $\mathrm{J}_{v}(\cdot)$ is the Bessel function of order $v$. A similar expression has been obtained by Dakoulas and Gazetas [2] for the seismic response of earthdams.

Noting that (Abramowitz and Stegun [3]):

$$
\lim _{z \rightarrow 0} \mathrm{~J}_{v}(z)=\left(\frac{z}{2}\right)^{v} \frac{1}{\Gamma(v+1)}+\mathcal{O}\left(z^{\nu+2}\right)
$$

where $\Gamma$ is the Gamma function, it is checked that the surface boundary condition is satisfied. The other boundary condition at $z=h$ gives the frequency equation:

$$
X(h)=0 \Rightarrow \mathrm{J}_{(p-1) /(2-p)}\left[\frac{2 \omega h}{V_{\mathrm{s}}(2-p)}\right]=0
$$

The eigenfrequencies are given by:

$$
f_{i}=\frac{\omega_{i}}{2 \pi}=\lambda_{i} \frac{V_{\mathrm{s}}(2-p)}{4 \pi h}
$$

where $\lambda_{i}$ is the $i$-th root of the Bessel function:

$$
\mathrm{J}_{(p-1) /(2-p)}\left(\lambda_{i}\right)=0
$$

Finally for convenience the mode shapes are normalized to unity at the ground surface $X_{i}(0)=1$; the final solution for the mode shapes is given, in dimensionless form, by:

$$
X_{i}\left(\frac{z}{h}\right)=\left[\frac{2}{\lambda_{i}}\right]^{(p-1) /(2-p)} \Gamma\left(\frac{1}{2-p}\right)\left(\frac{z}{h}\right)^{(1-p) / 2} \mathrm{~J}_{(p-1) /(2-p)}\left[\lambda_{i}\left(\frac{z}{h}\right)^{(2-p) / 2}\right]
$$

For a constant mass density with depth, the mode participation factors, $\alpha_{i}$, are:

$$
\alpha_{i}=\frac{\int_{0}^{1} X_{i}(u) \mathrm{d} u}{\int_{0}^{1} X_{i}^{2}(u) \mathrm{d} u}
$$

A closed form solution can be derived for the mode participation factor, but its numerical evaluation is not easy. Except for the special case $p=0$, it is better to compute $\alpha_{i}$ numerically from Eq. (11).

Finally the maximum displacement response in each mode is given by:

$$
u_{i}(z)=\alpha_{i} S_{\mathrm{d}}\left(\omega_{i}, \xi_{i}\right) X_{i}\left(\frac{z}{h}\right)
$$

where $S_{\mathrm{d}}\left(\omega_{i}, \xi_{i}\right)$ is the spectral relative displacement of the input motion $\ddot{v}_{\mathrm{g}}$ for frequency $\omega_{i}$ and damping ratio $\xi_{i}$.

The maximum ground surface acceleration, which is close to the pseudo acceleration, due to the contribution of the first $N$ modes is:

$$
\ddot{u}_{\max }(z=0)=\left[\sum_{i=1}^{N}\left(\alpha_{i} S_{\mathrm{a}}\left(\omega_{i}, \xi_{i}\right)\right)^{2}\right]^{1 / 2}
$$


Table 1

Roots of Bessel equation and mode participation factors

Tableau 1

Racines de l'équation de Bessel et coefficients de participation modaux

\begin{tabular}{llrrrrr}
\hline$p$ & & \multicolumn{1}{c}{0.0} & 0.25 & \multicolumn{1}{c}{0.5} & \multicolumn{1}{c}{0.75} & \multicolumn{1}{c}{1.0} \\
\hline Mode 1 & $\lambda$ & 1.5708 & 1.7004 & 1.8664 & 2.0883 & 2.4048 \\
& $\alpha$ & 1.2732 & 1.3165 & 1.3760 & 1.4630 & 1.6020 \\
Mode 2 & $\lambda$ & 4.7124 & 4.8313 & 4.9879 & 5.2035 & 5.5201 \\
& $\alpha$ & -0.4244 & -0.5010 & -0.6104 & -0.7781 & -1.0648 \\
Mode 3 & $\lambda$ & 7.8540 & 7.9703 & 8.1243 & 8.3377 & 8.6537 \\
& $\alpha$ & 0.2546 & 0.3149 & 0.4068 & 0.5600 & 0.8514 \\
Mode 4 & $\lambda$ & 10.9956 & 11.1107 & 11.2635 & 11.4759 & 11.7915 \\
& $\alpha$ & -0.1819 & -0.2314 & -0.3099 & -0.4480 & -0.7297 \\
\hline
\end{tabular}

where $S_{\mathrm{a}}\left(\omega_{i}, \xi_{i}\right)=\omega_{i}^{2} S_{\mathrm{d}}\left(\omega_{i}, \xi_{i}\right)$ is the spectral pseudo acceleration. Eq. (13) takes into account the fact that the mode shapes have been normalized to 1 at the ground surface $\left(X_{i}(0)=1\right)$. With four modes the cumulative modal mass is greater than $90 \%$ (this property is even satisfied with three modes provided $p \leqslant 0.75$ ) and therefore the analysis can be restricted to the first three or four modes ( $N=3$ or 4). The roots $\lambda_{i}$ of the frequency Eq. (9) and the mode participation factor $\alpha_{i}$ for the first four modes are given in Table 1 for different values of the exponent $p$ in Eq. (1).

The shear strain is given, for each mode, by:

$$
\gamma_{i}(z)=\frac{\partial u_{i}(z)}{\partial z}=\alpha_{i} \frac{S_{\mathrm{a}}\left(\omega_{i}, \xi_{i}\right)}{h \omega_{i}^{2}} \frac{\mathrm{d} X_{i}(u)}{\mathrm{d} u}
$$

Given the relationship:

$$
\mathrm{J}_{v}^{\prime}(x)=\mathbf{J}_{v-1}(x)-\frac{v}{x} \mathbf{J}_{v}(x)
$$

the shear strain can be normalized to yield a quantity that is independent of the input motion and only depends on the soil profile through the exponent $p$ :

$$
\begin{aligned}
\chi_{i}\left(\frac{z}{h}\right)= & \frac{\gamma_{i}(z) \omega_{i}^{2}}{S_{\mathrm{a}}\left(\omega_{i}, \xi_{i}\right)} h=\alpha_{i}\left(\frac{2}{\lambda_{i}}\right)^{\nu} \Gamma\left(\frac{1}{2-p}\right) \\
& \times\left\{(1-p)\left(\frac{z}{h}\right)^{-(p+1) / 2} \mathrm{~J}_{v}\left(\lambda_{i}\left(\frac{z}{h}\right)^{(2-p) / 2}\right)+\lambda_{i} \frac{2-p}{2}\left(\frac{z}{h}\right)^{(1-2 p) / 2} \mathrm{~J}_{v-1}\left(\lambda_{i}\left(\frac{z}{h}\right)^{(2-p) / 2}\right)\right\}
\end{aligned}
$$

with $v=(p-1) /(2-p)$.

When $z$ tends to zero the normalized shear strain is equivalent to:

$$
\chi_{i}\left(\frac{z}{h}\right) \sim-\alpha_{i}(2-p)^{2}\left(\frac{\lambda_{i}}{2}\right)^{2}\left(\frac{z}{h}\right)^{1-p}
$$

It can be checked that the shear stress, which is equal to the shear strain times the shear modulus, tends to zero because $G$ is proportional to $z^{p}$. The normalized shear strain can be determined once and for all. Sample plots are shown in Fig. 1 for $p=0$ and $p=0.75$.

\section{Soil constitutive model}

A simplified elastic-perfectly plastic constitutive relationship (Fig. 2) is assumed for the soil layer; the shear stress-shear strain curve is defined by two parameters which may depend on the depth $z$ :

- the shear strength $\tau_{\max }(z)$;

- the yield strain $\gamma_{\mathrm{f}}(z)$. 

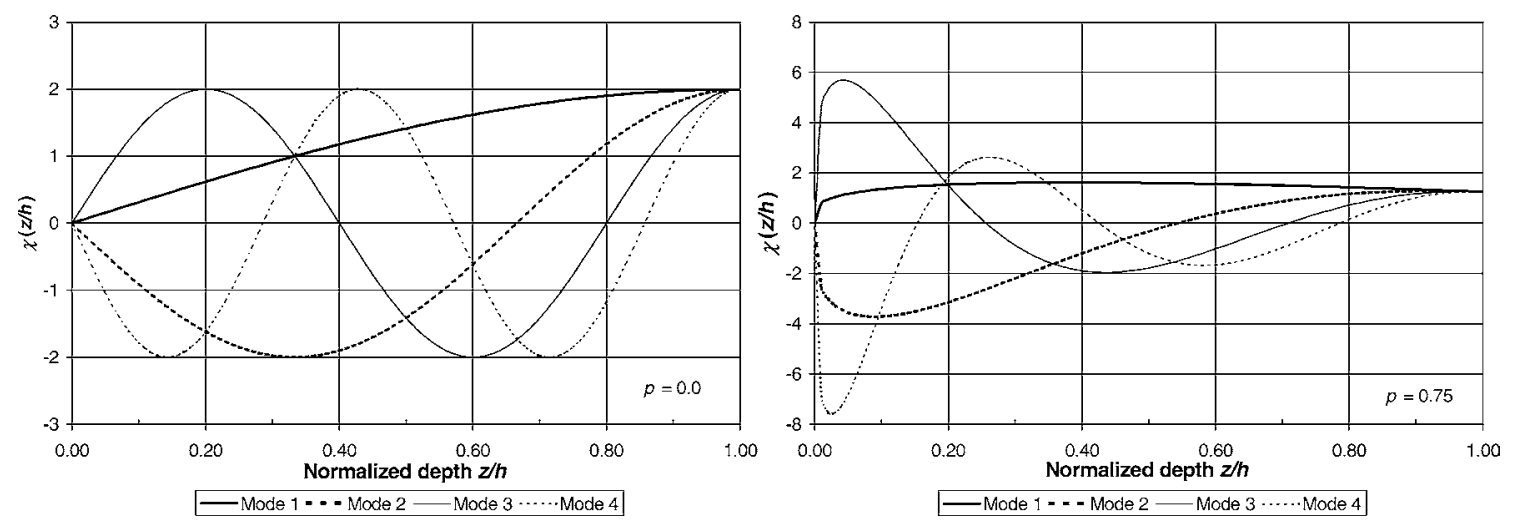

Fig. 1. Normalized shear strain versus normalized depth.

Fig. 1. Déformation de cisaillement normalisée en fonction de la profondeur normalisée.

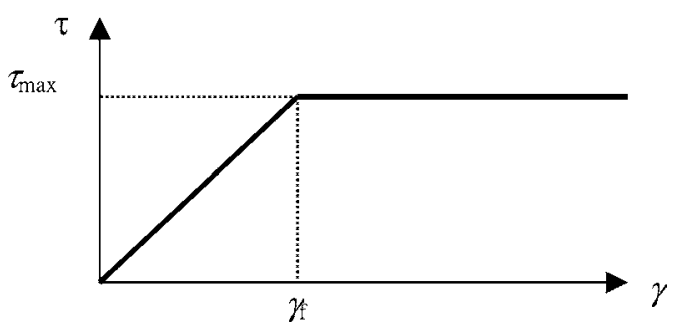

Fig. 2. Soil stress-strain behavior.

Fig. 2. Loi de comportement du sol.

The shear modulus is then given by $G=\tau_{\max } / \gamma_{\mathrm{f}}$.

As soon as, at any depth within the soil profile, the shear strain reaches $\gamma_{\mathrm{f}}$, the maximum shear stress that can be transmitted is limited by $\tau_{\max }$; the ground surface acceleration cannot therefore exceed the value reached when $\gamma(z)=\gamma_{\mathrm{f}}$.

The procedure involves the following steps:

(i) define the input motion at the rock interface by its pseudo acceleration response spectrum $S_{\mathrm{a}}^{*}$. This is typically the result of the PSHA;

(ii) compute the eigenfrequencies and mode participation factors from Eqs. (8) and (11);

(iii) plot the shear strain (Eq. (16)) versus depth together with the yield strain $\gamma_{\mathrm{f}}$;

(iv) determine the depth $z_{0}$ and the scaling factor $\mu$ for which $\gamma_{f}=\mu \gamma\left(z_{0}\right)$;

(v) define $S_{\mathrm{a}}=\mu S_{\mathrm{a}}^{*}$ the maximum possible pseudo acceleration from which the maximum ground surface acceleration $\ddot{u}_{\max }(z=0)$ is determined (Eq. (13)).

A table and a figure are provided for the relevant input data for the procedure defined above:

- Table 1 gives the mode participation factors $\alpha_{i}$ and the roots of the Bessel function for the first three modes, to be used for step (ii);

- Fig. 1 gives the variation of the normalized shear strain versus depth $\chi(z / h)$ for the first four modes and different values of the parameter $p$, to be used for step (iii). 


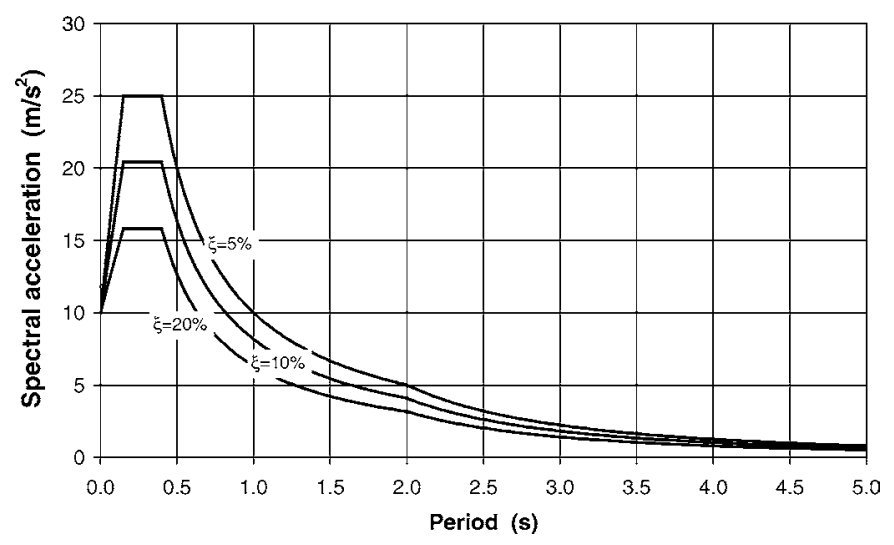

Fig. 3. Bedrock response spectrum.

Fig. 3. Spectre de réponse au rocher.

\section{Example of application}

Let us consider a site composed of $50 \mathrm{~m}$ of sand and gravel with a water table at $26 \mathrm{~m}$ depth. The shear strength is expressed by the Mohr Coulomb strength criterion $\tau_{\max }=\sigma_{v}^{\prime} \tan \left(\varphi^{\prime}\right)$ with a friction angle $\varphi^{\prime}=41^{\circ}$. The yield strength is equal to $3 \%$. From the constitutive relationship the variation of the shear wave velocity with depth can be approximated with $p=0.75$ and $V_{\mathrm{s}}=104 \mathrm{~m} / \mathrm{s}$. The bedrock motion is represented by the pseudo acceleration response spectrum of Fig. 3, scaled to $10 \mathrm{~m} / \mathrm{s}^{2}$.

The first three circular frequencies, which are required to achieve a modal mass greater than $90 \%$, are equal to: $\omega_{1}=2.72 \mathrm{rd} / \mathrm{s}, \omega_{2}=6.78 \mathrm{rd} / \mathrm{s}, \omega_{3}=10.87 \mathrm{rd} / \mathrm{s}$ and the corresponding spectral accelerations for $20 \%$ damping, which is relevant for a near failure condition, are equal to $S_{\mathrm{a} 1}^{*}=2.37 \mathrm{~m} / \mathrm{s}^{2}, S_{\mathrm{a} 2}^{*}=6.83 \mathrm{~m} / \mathrm{s}^{2}, S_{\mathrm{a} 3}^{*}=10.94 \mathrm{~m} / \mathrm{s}^{2}$. The yield strain becomes equal to the induced strain for $\mu=1.78$ at a critical depth of $3 \mathrm{~m}$ below the ground surface.

The associated spectral accelerations are: $S_{\mathrm{a} 1}=\mu S_{\mathrm{a} 1}^{*}=4.22 \mathrm{~m} / \mathrm{s}^{2}, S_{\mathrm{a} 2}=\mu S_{\mathrm{a} 2}^{*}=12.16 \mathrm{~m} / \mathrm{s}^{2}, S_{\mathrm{a} 3}=\mu S_{\mathrm{a} 3}^{*}=$ $19.47 \mathrm{~m} / \mathrm{s}^{2}$ from which the maximum peak ground acceleration (Eq. (13)) is equal to: $\ddot{u}_{\max }=15.7 \mathrm{~m} / \mathrm{s}^{2}$.

\section{Conclusions}

A simple method has been proposed to estimate the maximum ground surface motion that can reach the surface of a soil profile whatever the amplitude of the input rock acceleration. Tables and figures are provided that makes the method readily applicable to any soil profile and input motion. The proposed method is robust, because the shear strength is a parameter that is routinely measured, rather reliable, and also because the results are not sensitive to changes in the yield strain. For the example presented herein it has been compared to parametric numerical site response analyses based on a sophisticated soil constitutive model (multi-yield elastoplastic model with kinematic hardening) from which the maximum ground surface acceleration has been found equal to $12 \mathrm{~m} / \mathrm{s}^{2}$. When compared with actual earthquake records (Rosrine SMT site in California) it does not contradict the observations: the maximum recorded acceleration is equal to $8.9 \mathrm{~m} / \mathrm{s}^{2}$ whereas the predicted one using the above methodology is equal to $8.8 \mathrm{~m} / \mathrm{s}^{2}$.

\section{References}

[1] J. Betbeder Matibet, Calcul de l'effet de site pour une couche de sol. Troisième Colloque National de Génie Parasismique, Vol. 1, SaintRémy-lès-Chevreuse, March 1993, pp. DS1-DS10.

[2] P. Dakoulas, G. Gazetas, A class of inhomogeneous shear models for seismic response of dams and embankments, Soil Dynamics and Earthquake Engrg. 4 (4) (1985) 166-182.

[3] M. Abramowitz, I.A. Stegun, Handbook of Mathematical Functions, 9th edition, Dover, New York, 1970. 